\title{
Reação em Cadeia da Polimerase (PCR) baseada no gene cpx para detecção de Actinobacillus pleuropneumoniae em suínos natural e experimentalmente infectados
}

\author{
Polymerase Chain Reaction (PCR) based on the cpx gene for detection of Actinobacillus \\ pleuropneumoniae in natural and experimentally infected pigs
}

\author{
Karina Koerich de Souza ${ }^{\mathrm{I}}$ Catia Silene Klein ${ }^{\mathrm{I}}{ }^{*}$ \\ Jalusa Deon Kich" Arlei ColdebellaII \\ Geraldo Camilo Alberton ${ }^{\mathrm{I}}$
}

RESUMO

A pleuropneumonia suína é uma das mais importantes doenças respiratórias dos suínos, estando presente em todos os países produtores. Para o controle e o monitoramento da pleuropneumonia, é necessário o desenvolvimento de métodos rápidos e acurados de diagnóstico. Com o objetivo de validar a técnica da PCR, baseada no gene cpx de Actinobacillus pleuropneumoniae, em suínos sabidamente positivos, primeiramente foi realizada inoculação experimental com amostras de A. pleuropneumoniae sorotipo $5 B$ e coletadas amostras por meio de suabe de tonsila, biópsia de tonsila e sangue para realização da técnica de PCR, isolamento bacteriológico e teste de ELISA, respectivamente. Posteriormente, estas técnicas foram aplicadas em suínos naturalmente infectados, em três rebanhos com diferentes situações sanitárias quanto à apresentação clínica da doença. De cada rebanho, foram analisados cinco grupos de suínos com idades diferentes, sendo coletado de cada animal biópsia de tonsila para isolamento bacteriológico e PCR e sangue para determinação do perfil sorológico. Os resultados obtidos na inoculação experimental confirmaram que, mesmo com o estabelecimento da infecção comprovada pelo isolamento bacteriológico, após o período de 45 dias, não foi possível detectar o agente pela técnica de PCR. Em animais naturalmente infectados, a técnica de PCR apresentou maior sensibilidade quando comparado com o isolamento. A associação entre PCR e ELISA demonstrou ser uma boa alternativa para definir a situação sanitária do rebanho quanto à infecção por A. pleuropneumoniae.

Palavras-chave: suíno, Actinobacillus pleuropneumoniae, PCR, diagnóstico, gene cpx.

\section{ABSTRACT}

Swine pleuropneumonia is one of the most important pig respiratory diseases and has been found in all producer countries. For control and monitoring of pleuropneumonia, it is necessary the development of fast and specific methods of diagnosis. To validate PCR based on the cpx gene of Actinobacillus pleuropneumoniae in positive pigs, an experimental infection with A. pleuropneumoniae serotype $5 B$ was performed and samples were obtained by tonsil swab, tonsil biopsy and blood for PCR, bacterial isolation and ELISA, respectively. These tests were then performed in naturally infected pigs from three herds with different sanitary situations of clinical disease. In each herd, five groups of different ages were analyzed. Tonsil biopsy for bacterial isolation and PCR and blood to determine the herd serological status was collected. The results obtained in the experimental infection confirmed that, even with the infection establishment, proved with bacterial isolation, it was not possible to detect the agent by PCR 45 days after infection. In naturally infected animals, PCR was more sensitive than bacterial isolation. The association between PCR and ELISA is a good alternative to define the herd sanitary status regarding the infection with A. pleuropneumoniae.

Key words: swine, Actinobacillus pleuropneumoniae, PCR, diagnostic, срх gene.

\section{INTRODUÇÃO}

A pleuropneumonia suína, decorrente de infecção por Actinobacillus pleuropneumoniae, é amplamente distribuída, estando presente em todos os

'Departamento de Medicina Veterinária, Programa de Pós-graduação em Ciências Veterinárias, Universidade Federal do Paraná (UFPR), Curitiba, PR, Brasil.

"Embrapa Suínos e Aves, BR 153, Km 110, CP 21, 89700-000, Distrito de Tamanduá, Concórdia, SC, Brasil. Fone: (49) 34410400/Fax: (49) 3442-8559. E-mail: catia@cnpsa.embrapa.br.*Autor para correspondência. 
países onde a suinocultura é relevante. Ela é uma doença contagiosa, afetando animais de todas as idades, e causando lesões graves no pulmão e pleura. (TAYLOR, 1999).

O A. pleuropneumoniae é introduzido em rebanhos sem histórico clínico da doença após a aquisição de animais infectados. Animais convalescentes podem se tornar portadores do agente nas tonsilas e, menos freqüentemente, na cavidade nasal (INZANA, 1991; SIDIBÉ et al., 1993), sendo os principais transmissores entre os rebanhos (FENWICK \& HENRY, 1994). O agente é transmitido por via respiratória e se dissemina entre os animais, principalmente, pelo ar, entre baias adjacentes e/ou por contato direto. A prevalência da pleuropneumonia aumentou com a intensificação dos sistemas de produção em decorrência do estresse e do confinamento dos suínos. Freqüentemente, as granjas abrigam animais de origens e idades diferentes, oferecendo a oportunidade do surgimento de surtos a partir de infecções endêmicas (FENWICK \& HENRY, 1994).

No Brasil, na década de 90, os sorotipos de maior prevalência eram os 3, 5 e 7 (PIFFER et al., 1997). Na última década, os sorotipos 6,8 e 10 começaram a ser identificados e, atualmente, os de maior ocorrência são 5, 3 e 10 (KUCHIISHI et al., 2007).

O isolamento do A. pleuropneumoniae é definitivo na confirmação do diagnóstico da pleuropneumonia. Entretanto, quando aplicado a animais que não apresentam sinais clínicos (GRAM et al., 1996) ou com poucas células nas tonsilas (FITTIPALDI et al., 2003), o sucesso do isolamento bacteriano é baixo. Neste contexto, os métodos moleculares são ferramentas promissoras para um rápido diagnóstico etiológico, oferecendo várias vantagens quando comparados com testes bacteriológicos utilizados na rotina de laboratório (MURDOCH, 2003). Na detecção do A. pleuropneumoniae, a utilização da reação em cadeia da polimerase baseada no gene cpx (PCRcpx) apresenta grande especificidade, além de obter amplificação para todos os sorotipos, com exceção do sorotipo 4 (KLEIN et al., 2003).

Para definir a situação sanitária de uma granja e estudar a dinâmica da infecção, o uso combinado de testes imunológicos e PCR oferece melhores informações para a interpretação dos resultados (NIELSEN, 1988). Os objetivos do presente estudo foram validar a PCRcpx em suínos inoculados experimentalmente e comparar as técnicas da PCRcpx, de isolamento bacteriológico e de ELISA em suínos naturalmente infectados procedentes de três rebanhos com diferentes situações sanitárias quanto à infecção por A. pleuropneumoniae.

\section{MATERIAL E MÉTODOS}

Suínos experimentalmente infectados

Foram utilizados quatro leitões Specific

Pathogen Free (SPF) com 94 dias de idade negativos para A. pleuropneumoniae nos testes de ELISA (LPSCL), isolamento bacteriológico (IB) e PCRcpx. Três leitões foram inoculados via intranasal com A. pleuropneumoniae sorotipo $5 \mathrm{~B}$, com diferentes concentrações para cada leitão, de 108 Unidades Formadoras de Colônias (UFC) $\mathrm{mL}^{-1}, 104 \mathrm{UFC} \mathrm{mL} \mathrm{mL}^{-1} \mathrm{e}$ 102UFC $\mathrm{mL}^{-1}$, na dose de $0,5 \mathrm{~mL}$ em cada narina. Um leitão não-inoculado foi mantido em contato. Após a inoculação, foram realizadas cinco coletas com intervalo de 15 dias das seguintes amostras: sangue, suabe de tonsila e fragmento de tonsila. Na última coleta, aos 75 dias pós-inoculação (PI), os leitões foram necropsiados e foi coletado material para IB (fragmento de tonsila e pulmão), além de sangue, suabe e biópsia de tonsila para realização do teste de ELISA e PCRcpx, respectivamente.

Para o acesso às tonsilas, o leitão foi contido e o material foi coletado com auxílio de abridor de boca e iluminação de uma lanterna. Após a realização dos suabes, foi introduzido o aparelho de biópsia esterilizado com álcool 70\% e foi coletada amostra do tecido tonsilar. O material tonsilar foi acondicionado em microtubo contendo $300 \mu \mathrm{L}$ de caldo seletivo Lincomicina-Bacitracina (LB) (PIJOAN et al., 1983) até a chegada ao laboratório. Após a etapa de IB, o conteúdo de cada microtubo foi adicionado a $5 \mathrm{~mL}$ do caldo LB e incubados a $37^{\circ} \mathrm{C}$ por 24 horas, como uma etapa de pré-enriquecimento para aumentar a população original de A. pleuropneumoniae. Após a incubação, foi realizada extração de DNA e PCRcpx, a partir de $1 \mathrm{~mL}$ do caldo de cultivo.

Suínos naturalmente infectados

As três técnicas foram aplicadas em rebanhos comerciais com produção de suínos em ciclo completo e diferentes situações sanitárias quanto à apresentação clínica da pleuropneumonia. Os rebanhos foram selecionados de acordo com os seguintes critérios: infecção aguda, infecção crônica e sem apresentação clínica da doença.

A granja com infecção aguda era localizada na região litorânea Sul de Santa Catarina, não executava vazio sanitário e era composta por 350 matrizes. Ela apresentava desuniformidade de lotes e sinais clínicos característicos de pleuropneumonia como tosse profunda, anorexia e apatia. Foi registrado surto de pleuropneumonia com 
isolamento de agente (amostra não-sorotipável) há aproximadamente oito meses antes da coleta. No abate, houve registro de pleurisia e condenação por abscessos, após o qual foi estabelecido programa de vacinação.

A granja com infecção crônica era localizada na região Oeste de Santa Catarina, não executava vazio sanitário e possuía 17 matrizes. O rebanho não apresentava sinais clínicos de pleuropneumonia, mas havia registro de pleurisia e condenação de pulmão por nódulos e abscessos. Foi registrado surto de pleuropneumonia no ano de 1993, com isolamento do A. pleuropneumoniae sorotipo $5 \mathrm{~B}$ e atualmente, não havia programa de vacinação.

O rebanho sem apresentação clínica da doença era localizado na região Oeste do Paraná, executava vazio sanitário e possuía 215 matrizes. Não foram observados sinais clínicos no rebanho, não havia registro da doença, tampouco histórico de pleurisia ou condenação de pulmão por nódulos e abscessos no abate e não havia programa de vacinação para pleuropneumonia.

Foram amostrados 20 leitões em cinco cortes horizontais nas idades de: 11 , 13, 15, 17 e 19 semanas, totalizando 100 por granja. No rebanho com infecção crônica foram coletados 13 leitões com 11 semanas de idade, 10 leitões com 17 semanas de idade e 19 leitões com 19 semanas de idade, totalizando 82 amostras.

\section{Isolamento bacteriológico}

O fragmento de tonsila e pulmão foi submetido ao IB por meio de semeadura direta em ágar sangue com uma estria perpendicular de Staphylococcus aureus e semeadura direta em meio de cultivo sólido modificado por KICH et al. (2000), com PPLO ágar contendo cristal violeta $2 \mathrm{mg} / \mathrm{mL}$, NAD $10 \mathrm{mg}$ $\mathrm{mL}^{-1}$, lincomicina $1 \mathrm{mg} \mathrm{mL}^{-1}$ e bacitracina $1,4 \mathrm{mg} \mathrm{mL}^{-1}$. Todos os cultivos foram incubados a $37^{\circ} \mathrm{C}$, numa atmosfera entre 5 e $10 \%$ de $\mathrm{CO}_{2}$, por aproximadamente $18 \mathrm{~h}$.

\section{PCRcpx}

A técnica de extração do DNA de A. pleuropneumoniae utilizada foi descrita por FAN et al. (1995). Os iniciadores para o gene cpx foram definidos por LO et al. (1998), os quais amplificam um fragmento de 715 pares de bases (pb), sendo os iniciadores cpxUP (5'TGGCGATACCGGAAACAGAGTC-3') e cpxDO (5'GCGAAAGGCTATGGTATGGGTATGG-3'). O teste de PCRcpx foi realizado conforme descrito por LO et al.
(1998), com modificações sugeridas por Klein et al. (2003) e SOUZA (2005). Brevemente, a reação para um volume final de $25 \mu \mathrm{L}$ foi padronizada para conter: $5 \mu \mathrm{L}$ de amostra de DNA; $10 \mathrm{mM}$ de Tris- $\mathrm{HCl}$ (pH 8,3); $50 \mathrm{mM}$ de $\mathrm{KCl} ; 2,5 \mathrm{mM}$ de $\mathrm{MgCl}_{2} ; 200 \mu \mathrm{M}$ de cada desoxinucleotídeo trifosfatado (dNTP, Promega Corporation; Cat. No. U1330); 30pmol de cada iniciador cpx; 1 Unidade (U) de enzima Taq DNA polimerase recombinante (Invitrogen ${ }^{\mathrm{TM}}$ Life Technologies; Cat. №. 11615-010); 1 U de anticorpo da Taq DNA Polimerase (Platinum ${ }^{\circledR}$ Taq Antibody; Invitrogen ${ }^{\mathrm{TM}}$ Life Technologies; Cat. №. 10965-010). As amostras foram submetidas a 30 ciclos constituídos de dois minutos a $57^{\circ} \mathrm{C}$, dois minutos a $72^{\circ} \mathrm{C}$ e um minuto a $94^{\circ} \mathrm{C}$, em termociclador e, posteriormente, à eletroforese em gel de agarose $(1,5 \%)$ contendo $0,5 \mu \mathrm{g} \mathrm{mL}^{-1}$ de brometo de etídio e visualizadas em luz ultravioleta. A análise estatística utilizada foi descritiva.

Um fragmento de DNA de $715 \mathrm{pb}$ amplificado por PCRcpx a partir de um isolado de campo, purificado de gel de agarose, foi seqüenciado. As condições do preparo da amostra e corrida eletroforética do DNA seguiram as recomendações do fabricante do kit Big Dye ${ }^{\mathrm{TM}}$ Terminator Cycle Sequencing Ready Reaction 3.0 v (Applied Biosystems - ABI; Cat. No. 4336915, 4336917, 4336919, 4336921, 4336923) e do equipamento ABI PRISM 377 (Applied Biosystems - ABI). A sequência obtida foi comparada à depositada no GenBank®.

\section{ELISA(LPS-CL)}

As amostras de soro foram submetidas ao teste polivalente de ELISA com antígenos lipopolissacarídeos de cadeia longa (LPS-CL) dos sorotipos 3, 5 e 7, extraídos com fenol, desenvolvido na Embrapa Suínos e Aves por MACHADO et al. (2001).

\section{RESULTADOS E DISCUSSÃO}

Suínos experimentalmente infectados

O único isolamento de $A$. pleuropneumoniae foi realizado de nódulo pulmonar identificado na necropsia em leitão inoculado com a maior concentração bacteriana (108UFC $\mathrm{mL}^{-1}$ ). Este animal apresentava lesões características de pleuropneumonia crônica, com pleurite fibrosa adjacente a nódulos pulmonares. Nestas condições, o isolamento do A. pleuropneumoniae confirma o diagnóstico (SIDIBÉ et al., 1993). Não houve isolamento a partir de suabes e biópsias de tonsila, mesmo utilizando meios de cultura seletivos, o que demonstra a dificuldade de 
recuperação da bactéria de animais portadores sadios. A evidência de infecção foi observada também pela soroconversão. Todos os animais foram positivos no ELISA desde a primeira coleta 15 dias pós-inoculação (PI).

$\mathrm{Na}$ primeira coleta, foi obtido resultado positivo na PCRcpx em todas as amostras de suabe (4/4) e em 2/4 das biópsias de tonsila. O número de positivos, observado em animais diferentes independente da diluição, diminuiu para $1 / 4$ aos 30 dias e o último resultado positivo foi obtido aos 45 dias PI (1/4). Estes resultados demonstraram que, mesmo com o estabelecimento da doença, comprovada pelo isolamento do A. pleuropneumoniae em nódulo pulmonar, a presença do agente e sua detecção no trato respiratório superior pode ser um evento transitório. Três condições podem estar relacionadas com estes resultados, o período de colonização bacteriana tonsilar estimada em 7-8 semanas (VIGRE et al., 2002), a quantidade de bactérias nas tonsilas inferior aos níveis de detecção da PCR (FITTIPALDI et al., 2003) e a interferência negativa de outras espécies bacterianas NAD-dependentes (SIDIBÉ et al., 1993). Os resultados obtidos neste estudo demonstraram a importância de coletar material de animais com diferentes idades, para que haja acompanhamento da infecção, desde o estabelecimento da mesma até uma possível eliminação do agente.

Suínos naturalmente infectados

O fragmento de DNA amplificado de uma amostra de campo do rebanho com infecção crônica foi sequenciado e apresentou identidade de 93,39\% com a seqüência do gene cpxCB do A. pleuropneumoniae depositada no GenBank ${ }^{\circledR}$, confirmando a especificidade do iniciador utilizado no teste para a detecção do agente.

A partir dos suínos naturalmente infectados também não foi possível isolar o A. pleuropneumoniae, demonstrando as mesmas dificuldades descritas na infecção experimental. Com relação aos resultados obtidos pela PCRcpx, o A. pleuropneumoniae foi detectado com maior positividade em animais com 11 semanas de idade, considerando os três rebanhos, concordando com os achados de KUCHIISHI (2003). Estudos anteriores utilizando suabe nasal em rebanhos infectados para o isolamento bacteriológico encontraram uma prevalência de 56,9\% (58/102) de leitões positivos entre 11-15 semanas de idade (KUME et al., 1984) e 30\% (12/40) com 12 semanas de idade (WILLSON et al., 1987). Para VIGRE et al. (2002), esta idade coincide com a queda da imunidade materna com níveis muito baixos entre a $8^{\mathrm{a}}$ e $12^{\mathrm{a}}$ semanas (GARDNER et al., 1991) e o aumento do número de
A. pleuropneumoniae nas tonsilas. O maior número de resultados positivos na PCR, neste período, indica o pico de transmissão horizontal do A. pleuropneumoniae.

A soroconversão ocorreu a partir da $13^{\text {a }}$ semana de idade, alcançando níveis altos de soropositividade na 15aㅗ semana. Este fato também foi observado por KUCHIISHI (2003) e compreende o período entre o contato do animal com o agente e o início da produção de anticorpos (Figura 1). Segundo ANDREASEN et al. (2000), o período de soroconversão

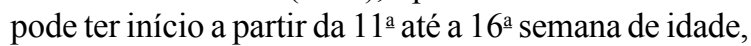
dependendo do sorotipo infectante.

No rebanho com infecção crônica (Figura 1), a PCRcpx detectou um número maior de animais positivos na $17^{\mathrm{a}}$ semana de idade e foram observados baixos níveis de soroconversão. A interpretação deste perfil deve considerar que o ELISA disponível é limitado aos sorotipos 3, 4, 5, 6, 7 e 8, o que pode explicar a discrepância entre resultados sorológicos e da PCR. Porém, para NIELSEN (1988), em infecções crônicas, a morbidade é baixa e a soroconversão só será observada em animais em que o patógeno invade o tecido pulmonar. O sorotipo pode estar presente no rebanho durante um tempo considerável antes de ser detectado, provavelmente como resultado de uma infecção mucosa latente sem indução da soroconversão, tornando os animais portadores (SIDIBÉ et al., 1993).

No rebanho com infecção aguda, foram observados poucos resultados positivos na PCRcpx, porém, um grande número de animais soropositivos (Figura 2). O pico de sorologia positiva coincide exatamente com a PCR negativa em todos os animais. Este rebanho adotava medidas de controle de pleuropneumonia, inclusive com programa de vacinação. A vacinação pode resultar em sorologia positiva, mas, por apresentar animais positivos na PCR e registro de surto de pleuropneumonia com diagnóstico laboratorial e isolamento do A. pleuropneumoniae, o perfil observado é compatível com rebanho que possui a infecção, porém, mantém a doença controlada pela vacinação. As vacinas comerciais diminuem a severidade da doença, mas não previnem o estado de portador do agente(FENWICK \& OSBURN, 1986).

No rebanho sem apresentação clínica da doença, também foram observados poucos resultados positivos na PCR e com menor número de soropositivos. Observa-se na figura 3 que a soroconversão acompanha os resultados da PCR. Entre os fatores que determinam a apresentação clínica da doença, estão a virulência do sorotipo presente na granja, o estado imunitário dos animais e o número de bactérias viáveis (FENWICK \& 


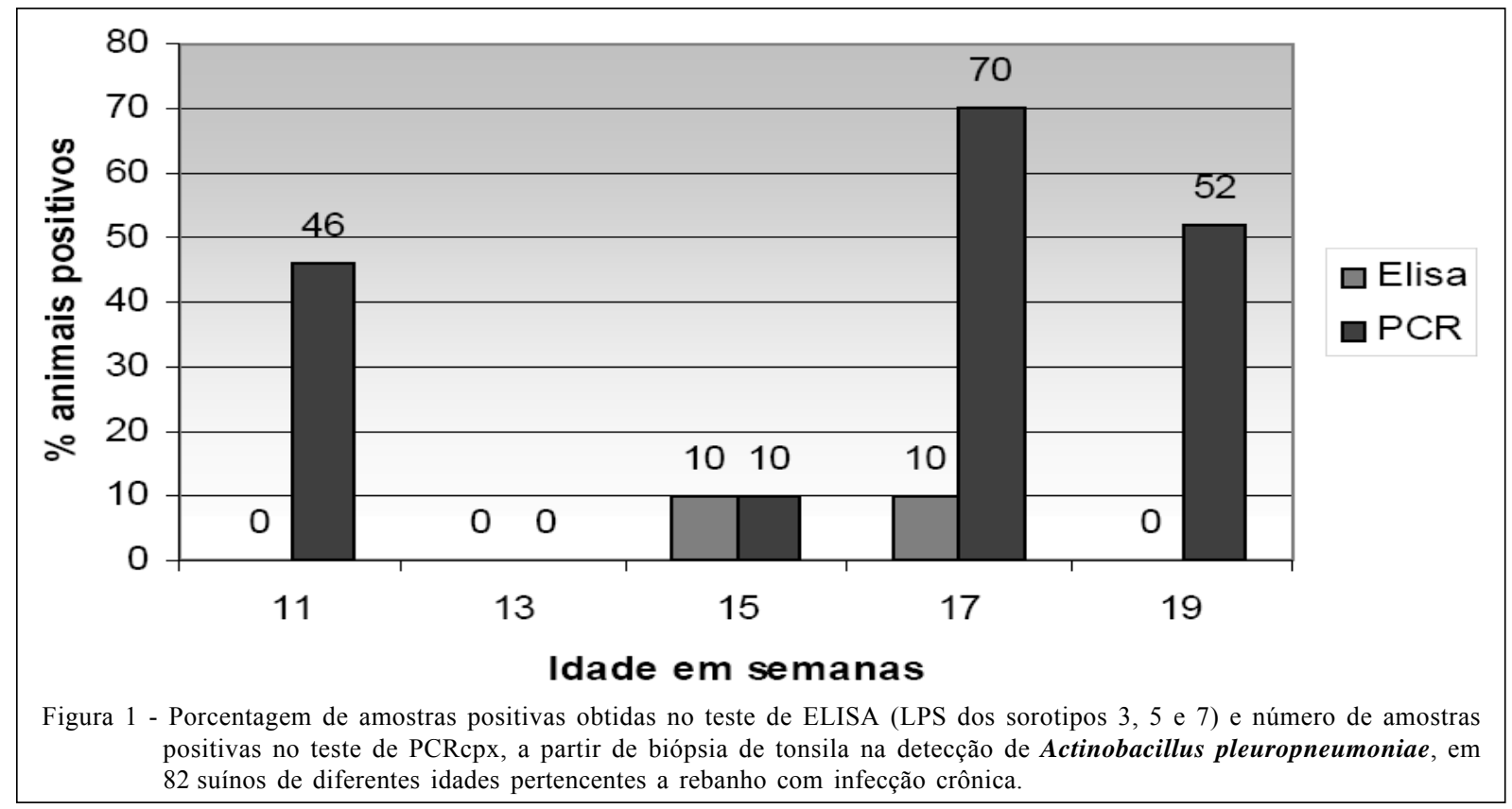

HENRY, 1994). Este rebanho não era vacinado, mas mantinha um estrito programa de biosseguridade, o que pode ter reduzido a pressão de infecção. Outro aspecto a ser considerado foi a não-dentificação do sorotipo presente, que pode também ser de baixa virulência.

\section{CONCLUSÃO}

A PCRcpx apresentou um número maior de resultado positivo que o isolamento bacteriológico. A associação entre PCR e ELISA é uma opção para definir a situação imune e sanitária do rebanho quanto à infecção por Actinobacillus pleuropneumoniae.

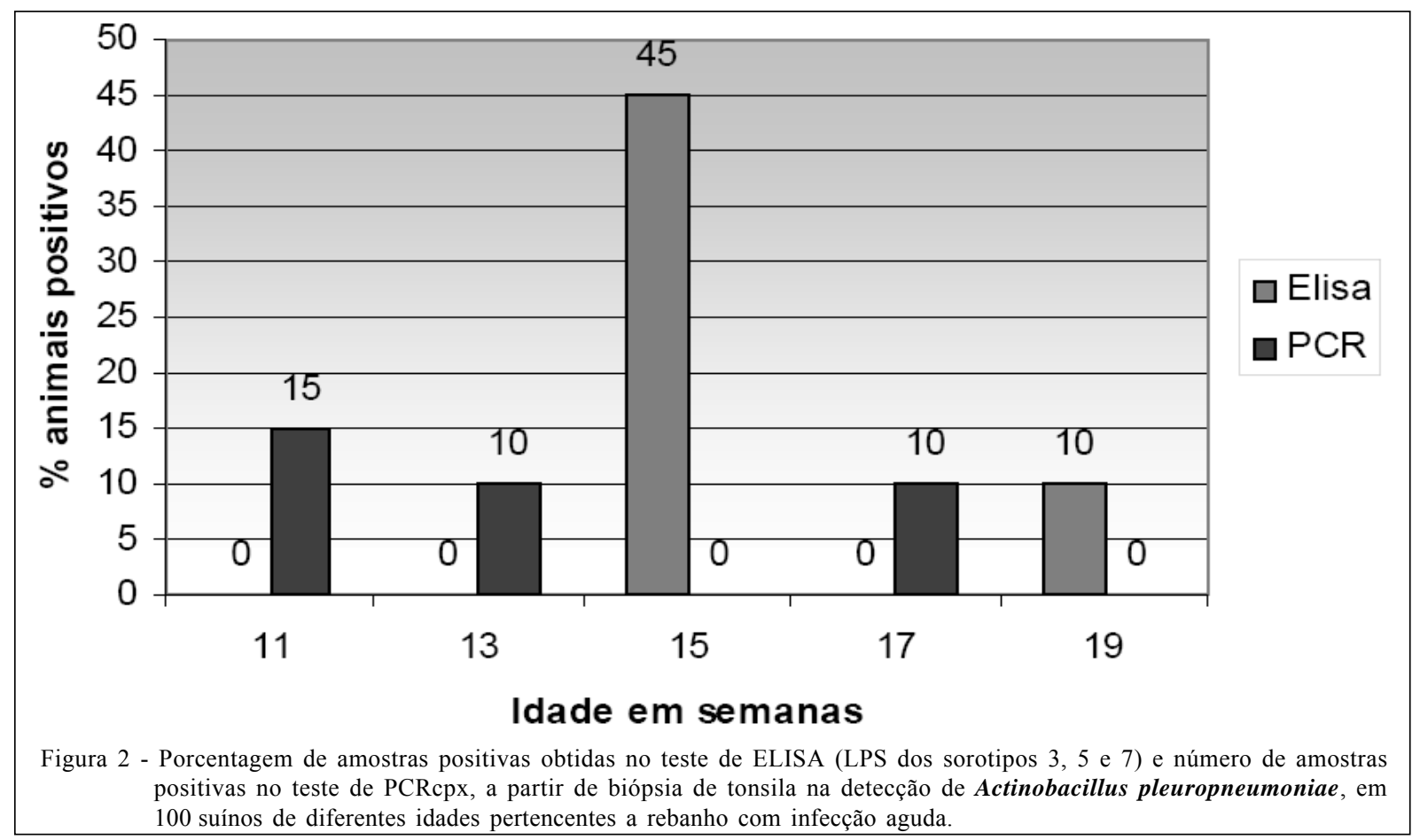

Ciência Rural, v.38, n.7, out, 2008. 


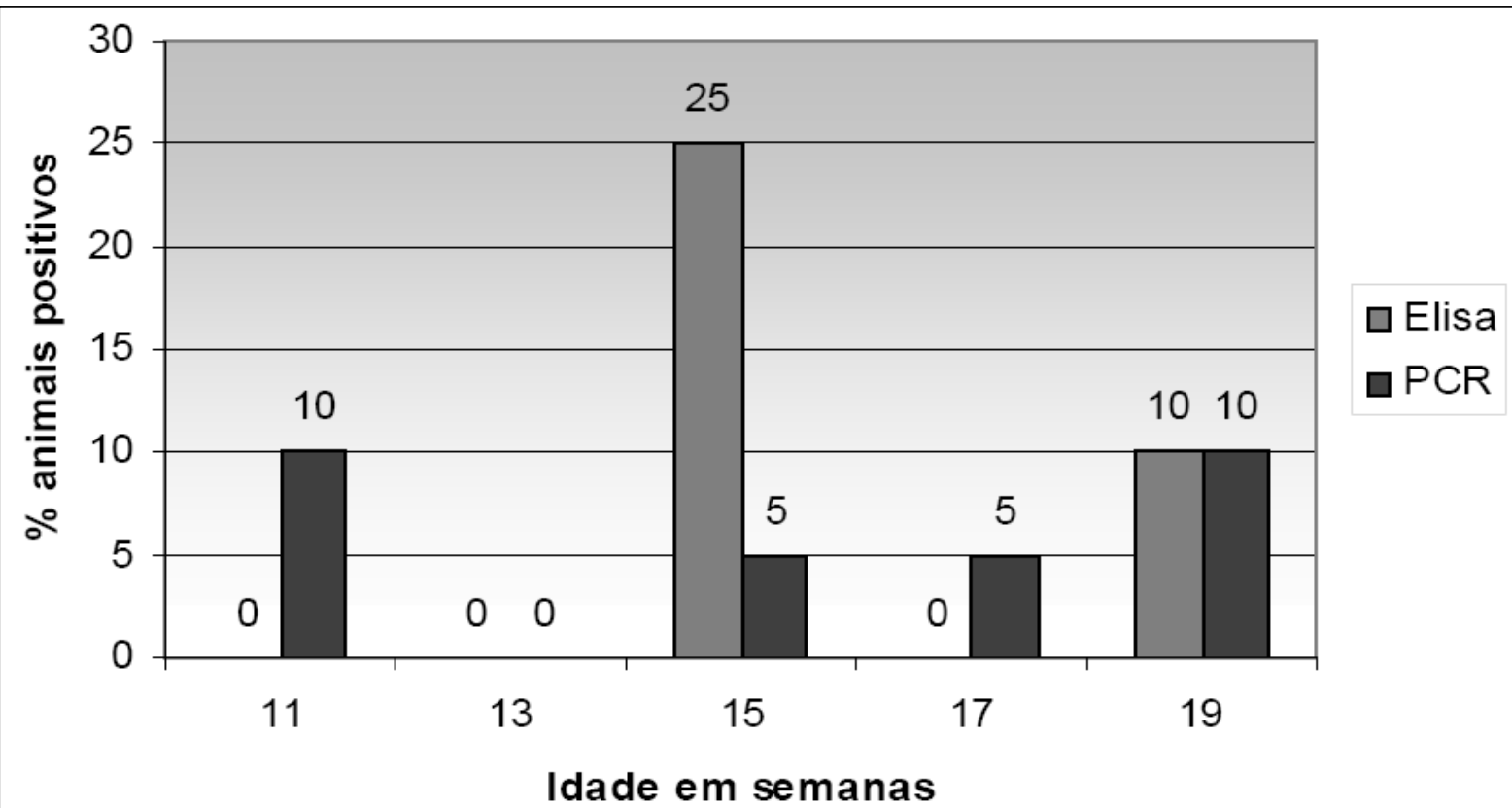

Figura 3 - Porcentagem de amostras positivas obtidas no teste de ELISA (LPS dos sorotipos 3, 5 e 7) e número de amostras positivas no teste de PCRcpx, a partir de biópsia de tonsila na detecção de Actinobacillus pleuropneumoniae, em 100 suínos de diferentes idades pertencentes a rebanho sem infecção clínica.

\section{REFERÊNCIAS}

ANDREASEN, M. et al. A longitudinal study of serological patterns of respiratory infections in nine infected Danish swine herds. Preventive Veterinary Medicine, Amsterdam, v.45, p.221-235, 2000 .

FAN, H.H et al. Aplication of Polymerase Chain Reaction with arbitrary to strain identification of Mycoplasma gallisepticum. Avian Diseases, Kennet Square, v.39, p.729-735, 1995.

FENWICK, B.W.; HENRY, S. Porcine pleuropneumonia. Journal the American Veterinary Medical Association, Schaumburg, v.204, n.9, p.1334-1340, 1994.

FENWICK, B.; OSBOURN, B.I. Immune responses to lipopolysaccharides and capsular polysaccharides of Haemophilus pleuropneumoniae in convalescent and immunized pigs. Infection and Immunity, Washington, v.54, p.575-582, 1986 .

FITTIPALDI, N. et al. Evaluation and field validation of PCR tests for detection of Actinobacillus pleuropneumoniae in subclinically infected pigs. Journal of Clinical Microbiology, Washington, v.41, n.11, p.5085-5093, 2003.

GARDNER, I.A. et al. Serological response to Actinobacillus pleuropneumoniae serovar 7 infection in a commercial pig herd. Australian Veterninary Journal, Victoria, v.68, n.11, p.349-352, 1991.

GRAM, T. et al. Evaluation of a PCR for detection of Actinobacillus pleuropneumoniae in mixed bacterial cultures from tonsils. Veterinary Microbiology, Amsterdam, v.51, p.95-104, 1996.
INZANA, T.J. Virulence properties of Actinobacillus pleuropneumoniae. Microbial Pathogenesis, London, v.11, p.305-316, 1991

KICH, J.D. et al. Comparação de métodos de isolamento de bactérias NAD-dependentes do trato respiratório superior de suínos sadios. Arquivo Brasileiro de Medicina Veterinária e Zootecnia, Belo Horizonte, v.52, n.1, p.1-6, 2000.

KLEIN, C.S. et al. Detection of Actinobacillus pleuropneumonie by PCR on field strains from healthy and diseased pigs. Current Microbiology, New York, v.46, p.443447,2003

KUCHIISHI, S.S. Avaliação de ensaio imunoenzimático indireto, isolamento bacteriológico tradicional e Reação em Cadeia da Polimerase no diagnóstico da pleuropneumonia suína. 2003. 72f. Dissertação (Mestrado) - Curso de Pós-graduação em Clínica Médica Veterinária, Universidade Estadual Paulista.

KUCHIISHI, S.S. et al. Sorotipos de Actinobacillus pleuropneumoniae isolados no Brasil de 1993 a 2006. Acta Scientiae Veterinariae, Porto Alegre, v.35, p.79-82, 2007.

KUME, K. et al. Isolation of Haemophilus pleuropneumoniae from the cavities of healthy pigs. Japanese Journal of Veterinary Science, Tokio, v.46, n.5, p.641-647, 1984.

LO, T.M. et al. Detection and identification of Actinobacillus pleuropneumoniae serotype 5 by multiplex PCR. Journal of Clinical Microbiology, Washington, v.36, p.1704-1710, 1998.

MACHADO, H.G. et al. Avaliação de testes de ELISA para o diagnóstico sorológico de infecções pelos sorotipos 3,5 e 7 de 
Actinobacillus pleuropneumoniae em suínos. Arquivo Brasileiro de Medicina Veterinária e Zootecnia, Belo Horizonte, v.53, n.5, p.513-522, 2001.

MURDOCH, D.R. Nucleic acid amplification tests for the diagnosis of pneumonia. Medical Microbiology, Texas, n.36, p.11620-1170, 2003.

NIELSEN, R. Seroepidemiology of Actinobacillus pleuropneumoniae. Canadian Veterinary Journal, Ottawa, v.29, p.580-582, 1988.

PIFFER, I.A. et al. Caracterização bioquímica e sorológica de 55 amostras de Actinobacillus pleuropneumoniae isoladas no Brasil. Arquivo Brasileiro de Medicina Veterinária e Zootecnia, Belo Horizonte, v.49, p.123-129, 1997.

PIJOAN, C. et al. Dilution technique for isolation of Haemophilus from swine lungs collected at slaughter. Journal of Clinical Microbiology, Washington, v.18, n.1, p.143-145, 1983.

SIDIBÉ, M. et al. Detection of Actinobacillus pleuropneumoniae in the upper respiratory tract as a complement to serological tests. Canadian Journal of Veterinary Research, Ottawa, v.57, p.204-208, 1993.

SOUZA, K.K. Otimização e aplicação da técnica de Reação em Cadeia da Polimerase (PCR) baseado no gene cpx de Actinobacillus pleuropneumoniae em suínos experimentalmente e naturalmente infectados. 2005. 81f. Dissertação (Mestrado) - Curso de Pós-graduação em Ciências Veterinárias, Universidade Federal do Paraná.

TAYLOR, D.J. Actinobacillus pleuropneumoniae. In: STRAW, B.E. et al. (Eds.). Diseases of swine. Ames: Iowa State University, 1999. p.343-354.

VIGRE et al. Transmission of Actinobacillus pleuropneumoniae in pigs under field-like conditions: emphasis on tonsillar colonization and passively acquired colostral antibodies. Veterinary Microbiology, Amsterdam, v.89, p.151-159, 2002 .

WILlsON, P.J. et al. Detection of Actinobacillus pleuropneumoniae infection in pigs. Canadian Veterinary Journal, Ottawa, v.28, n.3, p.111-116, 1987. 